УДК 173

\title{
РАЗВИТИЕ ТВОРЧЕСКОГО МЫШЛЕНИЯ СТУДЕНТОВ СРЕДСТВАМИ КОМПЬЮТЕРНОЙ АНИМАЦИИ
}

\section{Корыгин Артем Игоревич}

Аннотация: Статья посвящена развитию творческого мышления студентов художественно - графического факультета при помощи средств компьютерной анимации. Актуализация и доступность создания компьютерной анимации в современном мире неизбежно приводит к появлению ее в образовательной среде. В статье приводится анализ особенностей проявления творческого мышления в образовательной среде, а также влияние информационных технологий на проявление творчества обучающихся в учебной работе. Приведены примеры включения компьютерной анимации в образовательный процесс в качестве самостоятельной учебной дисциплины. Особое внимание уделено педагогическому аспекту использования анимации в формировании творческого мышления обучающихся. Определенно, что компьютерная анимация может быть, как средством, так и катализатором развития творческого мышления студентов.

Ключевые слова: Медиатехнологии, творческие способности, творческое мышление, компьютерная анимация, визуализация данных.

\section{DEVELOPMENT OF CREATIVE THINKING OF STUDENTS BY MEANS OF COMPUTER ANIMATION}

\section{Korygin Artem Igorevich}

\begin{abstract}
The article is devoted to the development of creative thinking of students of the art - graphic faculty with the help of computer animation. The actualization and availability of the creation of computer animation in the modern world inevitably leads to its appearance in the educational environment. The article analyzes the features of the manifestation of creative thinking in the educational environment, as well as the influence of information technology on the manifestation of students' creativity in educational work. Examples of the inclusion of computer animation in the educational process as an independent educational discipline are
\end{abstract}


given. Special attention is paid to the pedagogical aspect of using animation in the formation of students' creative thinking. It is certain that computer animation can be both a means and a catalyst for the development of students' creative thinking.

Key words: Media technology, creativity, creative thinking, computer animation, data visualization.

Образовательная система - это комплекс институтов образования, имеющей долгую и сложную историю. Начиная с древнейших времен, когда образование представляло собой разрозненную систему философских школ (платонизм, пифагорская школа, аристотелизм), педагогический процесс всегда был подвержен появлению новых проблем образования. С тех пор образование пережило серию эволюционных перемен в виде появления большого числа образовательных учреждений, в том числе дополнительного образования, вебинаров, образовательных ресурсов, различных методических и учебных материалов. Кроме видов, форм организации образования, а также насыщения образовательной среды изменились и подходы к образовательному процессу. Так, гуманизация общества изменила методы обучения и воспитания, включив формирование и становление отношений между обучающимися, развитие чувства собственного достоинства и повышение уровня знаний и профессиональных компетенций. Однако, не смотря на серьезные эволюционные изменения, система образования древнейшего времени и современности имеет одну общую характеристику - лабильность и стремление к актуализации знаний и различных обучающих средств, используемых в учебном процессе. Наряду с этим в процессе эволюции образование пыталось решить еще одну важную задачу - развитие у обучающихся творческого мышления.

Проблема творчества в рамках образовательной деятельности была исследована в трудах многих известных мыслителей и ученых. Так, Сократ, Платон, Аристотель относили творчество к божественному явлению, Психологи творчество рассматривали как часть развития личности. Л.С. Выготский, затем А.К. Маркова выделили творчество как проявление новизны в деятельности человека, возникающей на основе опыта, новых комбинаций действий или новых идей. Масштабные исследования данной проблемы лишний раз говорят о том, что процесс развития творческих способностей личности бы важен во все времена, причем, вне зависимости от сферы деятельности человека. Список сфер деятельности человека, в которых 
развивается творческое мышление обозначить невозможно, поскольку проявление творчества так или иначе неразрывно связанно со способностью человека к самостоятельной деятельности. В современном мире это связанно не только с возможностью человека генерировать новые идеи, но и с умением самостоятельно находить новые подходы к решению поставленных задач в определенных условиях осуществляемой деятельности.

Следует отметить, что методик или технологий развития творческого или креативного мышления много. Особенно хорошо этот вопрос проработан в сфере изобразительного, декоративно-прикладного искусства и дизайна.

Это связанно с повышенным требованием к реализации личных творческих идей учащихся. В течении всего обучения студенты занимаются генерацией различных идей и концепций под присмотром педагога, который помогает выстроить правильный рабочий план и, в результате, реализовать идею студента. Такой подход неизбежно приводит к творческому поиску, благодаря которому создается основа для успешного развития творческого мышления студентов. Однако, развитое творческое мышление необходимо не только в сфере искусства. Практически любая профессиональная деятельность нуждается в нестандартном подходе к работе к решению старых проблем новыми методами.

Объединяя вышесказанное, можно утверждать, что современное образование показывает потребность в использовании средств ИКТ для решения проблематики, связанной с развитием творческого мышления. Актуальность данного вопроса так же обуславливается цифровизацией образовательных учреждений и появлением электронных образовательных площадок. Все большее количество образовательных учреждений прибегают к созданию собственных электронных образовательных ресурсов (ЭОР) и использованию разнообразного программного обеспечения для дистанционной коммуникации с студентами (Zoom, Skype, Microsoft Teams и др.). В связи с увеличением роли средств ИКТ в современном образовании, увеличивается спрос на образовательные материалы, наполняющие такого рода ресурсы.

В поисках эффективного средства развития творческого мышления студентов, следует обратить внимание на компьютерную анимацию. Вопервых, обладая универсальностью программных средств и визуального языка, анимация может использоваться в образовательном процессе в разнообразных видах. Во-вторых, актуальность использования компьютерной анимации в образовательном процессе напрямую связанна с еe обширным распространением в современном мире. Технологии анимации используются в 
рекламе, пользовательских интерфейсов, презентациях, медиа-контенте. Отдельное внимание следует уделить содержанию образовательных программ используемых для наполнения мультимедийных интерактивных онлайн-курсов (МИОК) и информационных образовательных сред (ИОС). Использование компьютерной анимации в таких проектах позволяет усилить восприятие контента студентами, задействовав теоретический и практический материал.

Предполагается два варианта использования средств компьютерной анимации для развития творческого мышления студентов. Первый вариант заключается в использовании компьютерной анимации как самостоятельной дисциплины в процессе обучения студентов. В ходе выполнения заданий студенты неизбежно сталкиваются с определенными проблемами, требующими от них творческого подхода. Личная концепция, появившаяся в голове студента, проходит через сложный процесс создания, в ходе которого активизируются различные виды деятельности и мышления. Так как компьютерная анимация явление многогранное и сложное, представляющее собой синтез звука, движения и образов, студенту приходится учитывать все эти особенности при создании конечного продукта. Однако, благодаря инструкции педагога, обучающийся имеет четкий вектор движения в процессе работы. Он самостоятельно проходит через процесс рождения идеи, анализа различной информации, и последующего представления творческого контента. «Природой творческого мышления выступает синтез интеграции и систематизации знаний, предшествующего опыта эмоциональных переживаний и особенности психических свойств личности. Художественное творчество синкретично связано с эстетическим преобразованием окружающей среды и отвечает эстетическим потребностям людей. Развитие образного мышления, эмоциональное и ассоциативное сопереживание являются условием реализации художественного творчества. Продуктом такой творческой деятельности становится живописный образ, выраженный в виде произведения искусства в материальном объекте». [1, с. 213]. При данном подходе происходит активизация творческой активности студента, развитие его самостоятельности и готовности к будущей профессиональной деятельности. Искусство анимации объединяет большое количество понятий и явлений художественнографической и дизайнерской направленности. Многогранность и лабильность компьютерной анимации так же позволяет использовать ее на различных образовательных дисциплинах и в профессиональных сферах, не связанных с изобразительным искусством или дизайном.

Второй вариант использования компьютерной анимации для развития творческого мышления заключается в использовании ее как средства 
визуализации в образовательном инструментарии педагога. Подразумевается, что педагог, обладающий соответствующими знаниями и умениями в сфере ИКТ, может создавать и использовать образовательный медиа-контент как при очных занятиях, так и в рамках дистанционного образования. Анимация может использоваться в лекционных презентациях, интерактивных тестах, образовательных видеороликах. При этом грамотное использование компьютерной анимации усиливает восприятие студентами теоретического материала посредством аудиовизуальных образов. Связанно это с тем, что человеческий мозг лучше воспринимает информацию, которая представлена в графическом формате. «Обучение с использованием цифровых технологий позволяет реализовать многие дидактические принципы, например, наглядность, представленная в аудио-, фото-, видео-, которая активизирует внимание детей, усиливает их восприятие учебной информации, повышает эмоциональный фон, мотивацию к учению, формирует способы познания мира, собственной деятельности, развивая научный стиль мышления и творческие способности» [2, с. 123].

Таким образом, использование компьютерной анимации для развития творческого мышления может являться инструментом визуализации для педагога или же специализированной дисциплиной в процессе обучения студентов - бакалавров. Затрагивая последнее, необходимо отметить, что изучение компьютерной анимации студентами - дизайнерами необходимо в силу распространенности данной технологии в мировом пространстве. Как было отмечено выше, анимация используется везде - в рекламе, в разработке интернет-ресурсов, в искусстве, в научной деятельности. Развитое творческое мышление и умения работы в анимационной программной среде (Adobe Animate CC, Adobe After Effects), позволяет студентам вести эффективную профессиональную работу, побуждая их на самостоятельный творческий поиск и реализацию собственных идей.

Сущность вышеизложенного заключается в том, что на сегодняшний день образование испытывает необходимость в использовании мультимедиатехнологий. Одной из таких технологий является компьютерная анимация, обладающая широким спектром возможностей и лабильностью. В развитии творческих способностей студентов компьютерная анимации является технологией, позволяющей качественно подойти к образовательному процессу, учесть все нюансы студенческой аудитории.

Делая вывод из вышеописанного, образовывается вопрос, касающийся создания образовательных мультимедиа материалов и их внедрения в 
образовательную среду. Данный вопрос был изучен в процессе работы над научным исследованием по теме магистерской диссертации, в ходе которой была изучена литература и существующие электронные ресурсы.

В ходе исследования была разработан и создан проект для среды ЭОР по теме «Компьютерная анимация», в которой, в формате видео-уроков и лекций представлены задания и примеры их выполнения. Это удобный формат, с возможностью использования при очном и дистанционном образовании, для студентов - бакалавров и студентов - магистрантов.

Актуальность такого проекта заключается так же в том, что на художественно-графическом факультете МПГУ ранее не затрагивалась проблематика создания материалов для электронных образовательных ресурсов по дисциплине «Компьютерная анимация». Разрабатываемые медиа-материалы, в первую очередь, направлены на изучение программной среды для создания компьютерной анимации, таких как Adobe After Effects и Adobe Animate CC. Сущность созданных материалов заключалась в обучении студентов фундаментальных особенностей программной среды на примере определенных задач (Создания Анимированной кнопки, анимированного курсора). В ходе выполняемых заданий, у студентов происходила активизация творческой активности, заставляя их разрабатывать собственные концепции и вести последующую работу над ними.

Проведение педагогического эксперимента с использованием ЭОР дало положительные результаты. После выполнения заданий, была получена обратная связь от студентов, внесены правки в образовательные видеоролики. В последующей апробации, посредством обратной связи происходило улучшение качества образовательных роликов. Таким образом, видео-ресурсы были доведены до наилучшего состояния. Следуя этому можно утвердить следующие преимущества:

- Удобный доступ к образовательным материалам, возможность остановки видео и повторного просмотра;

- Структурированность материала и логичность повествования;

- Широкие возможности настройки образовательных медиа-материалов - перевода на иностранный язык, добавление новой информации;

Важно отметить роль обратной связи в педагогическом процессе с использованием образовательного медиа-контента. Так как группы студентов разнообразны по уровню знаний и умений, у некоторых студентов могут быть вопросы, на которые они не всегда могут получить ответы с помощью видео. Для связи со студентами необходимо использовать веб-средства, электронную почту и месседжеры, в зависимости от цели педагога. 
Полученные данные свидетельствуют о том, что методика оказалась эффективной: наблюдалась инициативность студентов, заинтересованность в образовательном процессе. При работе над созданием компьютерной анимации в программной среде студенты производили творческий поиск, анализ соответствующей информации, что благоприятно сказывалось на формировании их творческих способностей.

В связи с этим, разработанные материалы способствуют развитию творческого потенциалу студентов в работе с компьютерной анимацией.

В заключение можно сделать ряд выводов:

- Занятия по компьютерной анимации позволяют решать сложные задачи развития творческого мышления;

- Активизация творческого мышления студентов происходит посредством выполнения четко поставленного задания, выполнение которого требует от обучающегося самостоятельного решения о виде создаваемой анимации и ее последующей презентации;

- В качественно выстроенной образовательной среде, создаётся благоприятная доверительная эмоциональная обстановка, способствующая продуктивному образовательному процессу;

- Компьютерная анимация позволяет проявить у студентов гибкость мышления, что обусловлено умениями выявлять различные свойства объектов, в ходе работы переключаться с одного объекта на другой;

Таким образом, компьютерная анимация является эффективным средством развития творческих способностей студентов, как будущих педагогов, так и будущих дизайнеров. Особая ценность анимации заключается в ее открытости для различной среды, методических приемов и технологий, содействуя развитию творческого мышления и познавательной деятельности различных возрастных групп и категорий обучающихся, с возможностью включения в любую существующую методику обучения.

\section{Список литературы}

1. Катханова Ю.Ф., Дун Ю. Творческое мышление художника-педагога как основа гармоничного цветовосприятия. Право и практика. Издательство: АНО "Научно-исследовательский институт истории, экономики и права" (Москва) ISSN: 2411-2275 № 3. 2017. С. 212-216.

2. Катханова Ю.Ф. Творческие способности и их развитие в графической деятельности // монография - Чебоксары: ИД «Среда», 2018. С. 140. 